
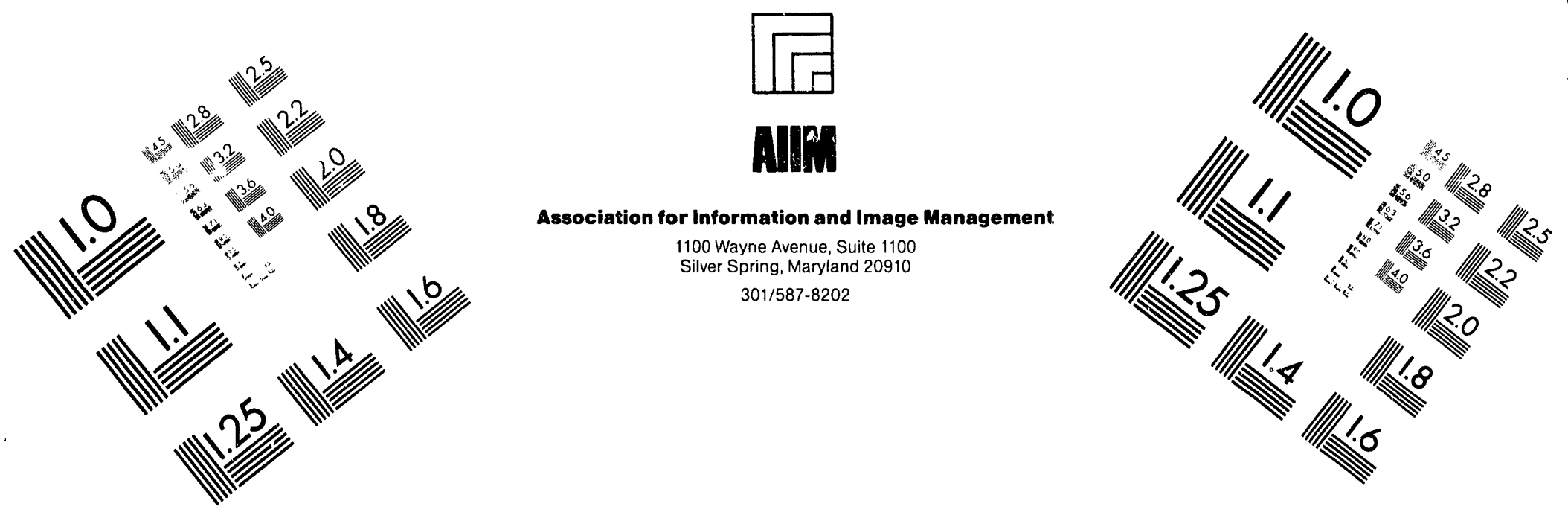

Centimeter

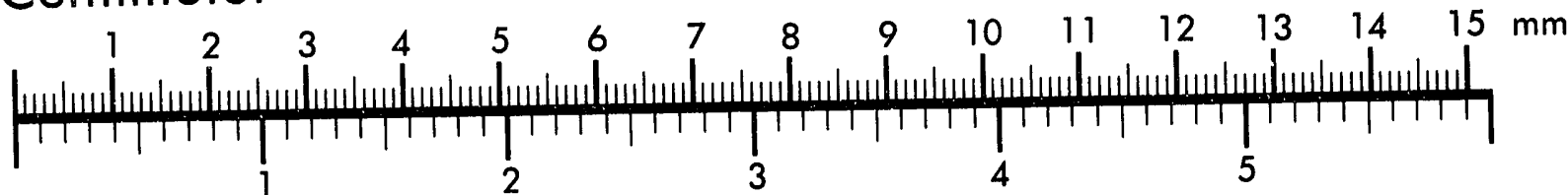
Inches
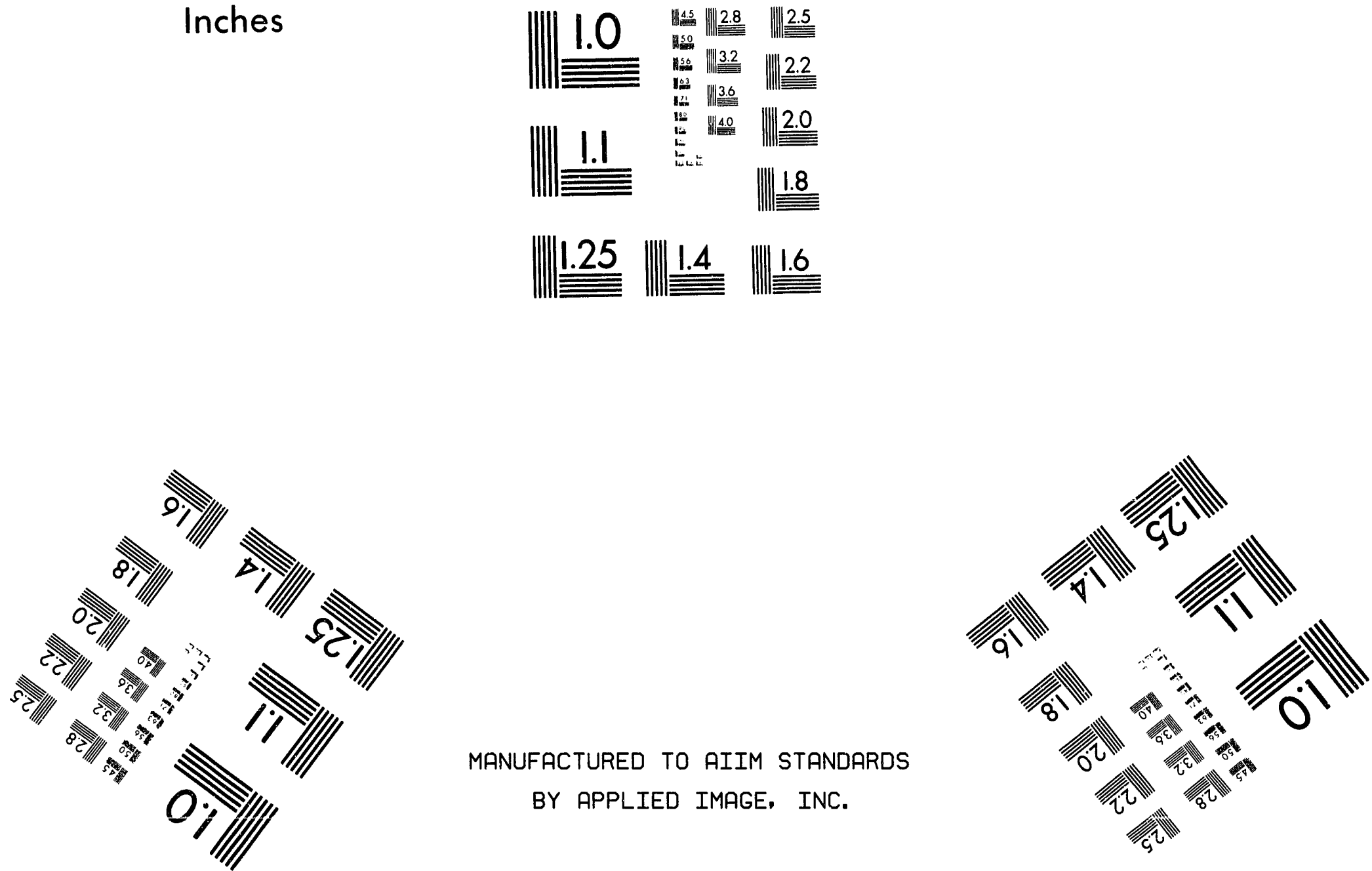

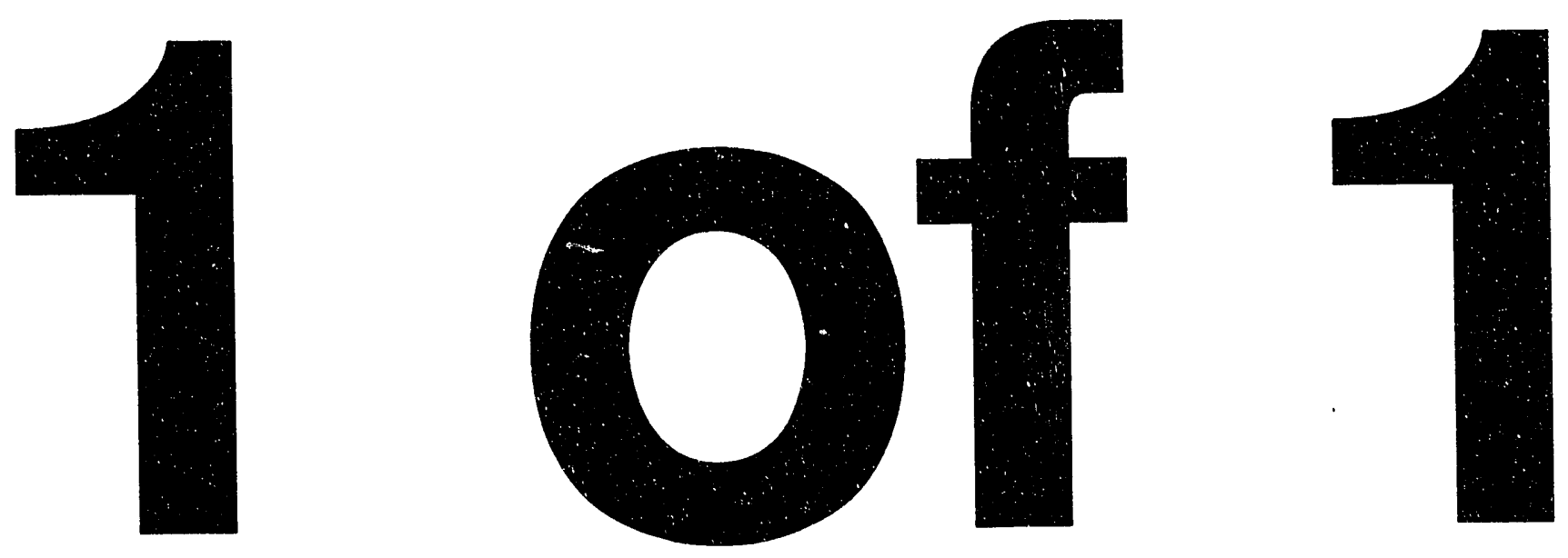


\section{A RISK-BASFD APPROACH TO COST-BENEFIT ANALYSIS OF SOFTWARE SAFETY ACTIVITIES}

\author{
Stephen C. Fortier \\ Intermetrics, Inc. \\ 7918 Jones Branch Drive, Suite 710 \\ McLean, Virginia 22102
}

\author{
J. Bret Michael \\ Argonne National Laboratory \\ 9700 South Cass Avenue \\ Argonne, Illinois 60439
}

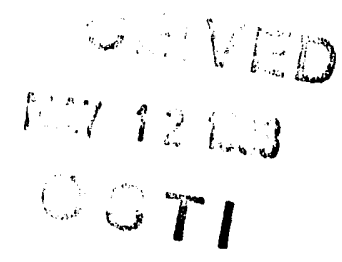

\begin{abstract}
Assumptions about the economics of making a system safe are usually not explicitly stated in industrial and software models of safety-critical systems. These assumptions span a wide spectrum of economic tradeoffs with respect to resources expended to make a system safe. The missing component in these models that is necessary for capturing the effect of economic tradeoffs is risk. A qualitative risk-based software safety model is proposed that combines features of industrial and software systems safety models. The risk-based model provides decision makers with a basis for performing cost-benefit analyses of software safety-related activities.
\end{abstract}

\section{INTRODUCTION}

Study of the industrial safety domain gives excellent insight into workplace risks and the causal factors that identify risk. Combining the lessons learned from industrial safety models with software system safety models provides a foundation upon which to develop risk-based software safety models.

Risk-based models provide decision makers-customers, system developers, and so on-with a systematic approach upon which to perform cost-benefit analyses of system safety related activities. A formal process for defining and enacting software safety activities is also necessary in order for decision makers to deal with the complexity of large, safety-critical systems. For example, Michael and Fortier [14] provide confirming evidence for this requirement in their case study of informal software processes used to develop and maintain air traffic control software.

In this paper we survey industrial safety models and then examine how the risk component of these models relates to modeling software-controlled systems. A risk-based model supporting cost-benefit analyses of software safety activities is presented to illustrate its value and utility in managing and improving software process models applied to safety-critical software systems.

\section{INDUSTRIAL SAFETY MODELS}

Indusirial safety research has been a very active field since the eariy $1900 \mathrm{~s}$. Many models have evolved from these research efforts. This section reviews some of the better known industrial safety models.

\subsection{Heinrich's Axioms of Industrial Safety}

A systematic approach to addressing accident causation was first documented in the 1920 s by H. W. Heinrich. The "axioms of industrial safety" [8] are first set of formal principles and guidelines for industrial safety, and as such, have had an influence on subsequent industrial safety research and practice. The axioms address various components of industrial safety, including

\section{Theory of Accident Causation}

- Interface of worker and machine

- Relationship of frequency to severity of accidents

- Underlying reasons for unsafe acts

- Relationship of accident control to other management functions

- Fundamental responsibilities for getting things done in an organization

- Costs of accidents

- Relationship between safety and efficiency.

The first axiom, for example, asserts "the occurrence of an injury invariably results from a completed sequence of factors - the last one of these being the accident itself. The accident in turn is invariably caused or permitted directly by the unsafe act of a person and/or a mechanical or physical hazard." This axiom is frequently referred to in the industrial safety community as the "domino theory." Figure 1 illustrates the accident sequence.

Heinrich described the five dominos as integral elements of his accident causation model. They are

1. Ancestry and Social Environment: Recklessness, stubbornness, and undesirable traits of character may be passed along through inheritance.

2. Faults of Person: Inherited or acquired faults of person, such as recklessness, violent temper, nervous-

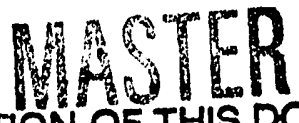

DISTRIBUTION OF THIS DOCUMENT IS UNLIMTTED

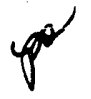



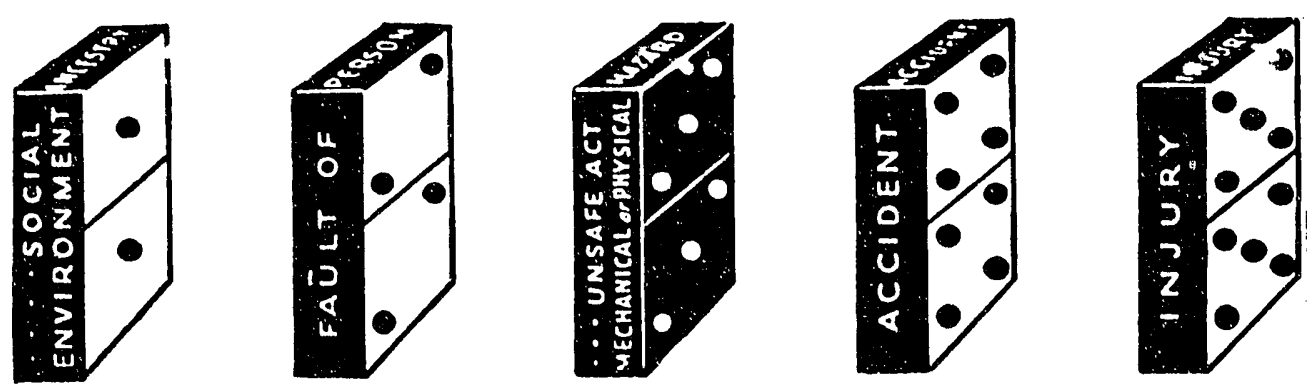

Figure 1. Heinrich's accident sequence

ness, excitability, inconsiderateness, ignorance of safe practice, constitute proximate reasons for committing unsafe acts or for the existence of mechanical or physical hazards.

3. Unsafe Act and/or Mechanical or Physical Hazard: Unsafe performance of persons, such as standing under suspended loads, horseplay, and removal of safeguards; and mechanical or physical hazards, such as unguarded gears, absence of rail guards, and insufficient light, result directly in accidents.

4. Accident: Events such as falls of persons, striking of persons by flying objects, are typical accidents that cause injury.

5. Injury: Fractures, lacerations, etc., are injuries resulting directly from accidents.

Heinrich attributed the basic causal factors primarily to human error. In contrast, more recent accident causation models emphasize management failures rather than human error.

\subsection{Bird's Five Domino Model}

In the 1970s, Frank Bird developed an updated version of Heinrich's domino sequence. Bird's model is based on management control of the safety process. He also developed a five domino model to explain the circumstances that lead to loss from industrial accidents [2].

The first domino in the sequence is a lack of management "control." Control refers to an integral element of basic management principles, including planning, organizing, leading and controlling. In particular, inadequate program planring, inadequate program standards, and failure to comply with standards are examples of lack of control. A lack of management control permits the existence of certain basic causes of incidents, degrading the optimal business process. These basic causes have also been referred to as root causes, since the substandard practices and conditions (immediate causes) most closely associated with the incident originate directly from them. In software engineering, examples of the basic causes are needs analysis, requirements definition, or risk analysis.
Bird's basic causes fall into the following two groups: (1) personal factors and (2) job factors. The personal factors are characterized by a lack of knowledge or skill, improper motivation and physical or mental problems, etc. Job factors are characterized by inadequate work standards, inadequate design or maintenance, inadequate purchasing standards, etc.

When the basic causes of incidents that could downgrade a business operation exist, they provide the opportunity for the occurrence of substandard practices and conditions (sometimes called errors) that could cause this domino (Immediate Causes-Symptoms) to fall and lead directly to loss. A substandard practice or condition (error) is any deviation from an accepted standard or practice. The practice can involve both acts of people and conditions related to physical things.

An undesired event that makes contact with a source of energy (above the threshold limit of body or structure) results in an Incident-Contact, according to Bird. Whenever substandard practices and conditions exist, there is a possibility for an incident to occur, which may or may not result in a loss. The incident is undesired, since the final results of its occurrence are difficult to predict and are most frequently a matter of chance.

Once the entire sequence has takel: place and there is a loss involved with people or property, the results are usually chance events in Bird's model. The element of chance is involved in quality and production losses as well as those of safety, health, and security.

Losses involved with different areas of the business activity can be classified as either minor, serious, major, or catastrophic. This categorization of loss has been adopted by the Department of Defense in MIL-STD$882 \mathrm{C}$ [7]. The results of accidents can be evaluated in terms of physical harm and property damage, as well as personal injury and economic effects. 


\subsection{Marcum's MIS-ACTS-InENT Sequence}

C. E. Marcum built upon the models proposed sy Heinrich and Bird; Marcum's Seven Domino Sequence Model [13] assumes that comprehensive analysis of occupational safety and associated health problems, issues, and concerns will reveal the existence of three interrelated modes in a sequential pattern of risk, hazard, and loss.

According to Marcum, accidents are avoidable if the proper safety policies, plans, and procedures are in place. He coined a term "MIS-ACTS-IDENT" as a substitute for the circumstances which surround accidental events. Accidental events are identifiable misacts that are related to a given harm-inflicting contact. The original definition of MIS-ACTS-IDENT emphasized the components of inadequate task preparation, substandard performance, mis-compensated risk, harmful contact, adverse reaction, sustained loss, and unwarranted cost.

Marcum contends that both managerial and supervisory personnel are the individuals who allow the sequential pattern of misacts to be initiated, to be continued, and also be repeated. He originated the idea that producing and servicing employees and their immediate supervisors do not have jurisdictional authority to act to circumvent risks, hazards, and losses. Necessary actions are in the purvicw of enterprise management and managerial personnel at higher levels in the organization.

During the carly 1980s, Marcum modified his domino sequence models to include greater emphasis upon risks, hazards, and losses, since these factors are considered to be the principal modes of any safety concern. These same three modes, therefore must become major thrusts of safety management practice, according to Marcum. No single individual can know all that is necessary to counteract all risks, hazards, and losses. However, competent safety managers will find ways to optimize the use of expertise that is available from a variety of sources.

\section{SOFTWARE SAFETY PARADIGMS}

For this paper, we adopt the following definition of safety with respect to software-controlled systems: "Safety is a measure of the continuous delivery of service free from occurrences of catastrophic failures" [4]. Leveson differentiates hazards from mishaps; ". . . hazards or states of the system ... when combined with certain environmental conditions could lead to a mishap" [12]. The attributes of a system state that constitutes a mishap are context dependent; that is, dependent on the usage of the software-controlled system. For example, a software failure of an automatic teller machine (ATM) in verifying customer withdrawal amounts can be considered a mishap from the financial institution's perspective if its customers suffer an economic loss as a result of the failure. In contrast, the same situation may not be consid- ered a mishap if the failure is detected and corrective action is take: prior th the financial institution, or its rustomers, sustaining losses.

There are various levels of safety, and the level of safety afforded by a system at any point in time is stated with respect to a particular system and definition of mishap. Software safety refers to ensuring the functions performed by software within a system context do not result in unacceptable risk. Risk is a function of the probability of a hazardous state resulting in a mishap.

Software reliability for software safety have different mcanings, although they are often used interchangeable. Software reliability is concerned with the probability of a failure occurring, and is tightly coupled to the specification of a system. A software failure is not necessarily equivalent to a mishap. A software failure can move a system into an unsafe system state, but a mishap may or may not occur during the duration of an unsafe state (c.g., the system may move through transient unsafe states before re-entering a safe state. This might happen when a system operator overrides the software in order to avert a mishap-the overriding of the software takes the system temporarily through an unsafe state).

There are two prominent software safety paradigms. In the first paradigm, safety is built into system requirements and then transformed into an implementation. The implementation is then verified against system safety requirements. This approach is described in [11]. In contrast, the other paradigm is based upon the assumption that it is possible to distinguish between safetycritical from non-safety-critical system functionality, and then build safety into the critical system functions. This would be accomplished through mathematical verification and testing of the system design and implementation (code) using software reliability and software trustworthiness as measures of conformance to safety statements. This paradigm is discussed in [15]. These two paradigms can be integrated to provide a more comprehensive approach to ensuring the safety of software-controlled systems.

What these safety paradigms are missing are a representation of risk for use in determining how much safety is necessary and sufficient for a given system and its intended and unintended uses; nor do they provide for relating risk to the resources required for ensuring a software-controlled system meets or exceeds a given level of safety. Both the software process activities associated with building or retrofitting safety into software-controlled systems result in the consumption by an enterprise of its resources.

\section{RISK-BASED SOFTWARE SAFETY MODEL}

The industrial safety risk-based models proposed by Heinrich, Bird, and Marcum provide starting points from 
which to explore the development and enactment of riskbascd software process models. A software process model is a representation of the sociotechnological issues and related system life-cycle activities. From a risk management perspective, a software process model is a plan embodying the management and engineering principles and practices for eliminating or mitigating actual and perceived risks to a software system. The plan can be for an entire system life cycle or for specific phases of a system life cycle. The costs and benefits associated with abiding by or contravening a plan is system-specific.

The potential for loss due to software failures increases as software is increasingly used to control safety-critical functions of a system. For instance, the electromechanical safety interlocks on some systems have been replaced with software. The potential for cost savings from implementing interlocks in software is flexibility; that is, modifications to software are often less costly than redesigning and remanufacturing a piece of hardware. What is needed is a systematic approach to analyzing software-related risk from a cost-benefit perspective.

We propose a microcconomic model for systematically analyzing the risks associated with the issues, principles, practices, and activities identified in a software process model. We refer to this model as the Riskbased Software Safety Model. In this model, risk criteria are imposed upon the software life-cycle model used by the developer of a software system. We chose, for illustration purposes, to use the Spiral Model of software development [3] because the Spiral Model caters to feedback and iteration among system life-cycle phases, both of which are recognized as necessary for improving the software process (e.g., see [9]). For example, adjustments need to be made to software process models to account for changes in the environment, system requirements, and so on. Life cycle and software process models are not an end in themselves; they are aids for use in decision making.

The basic tenet of the Risk-based Software Safety Model is that managers, engineers, and customers (i.e., the people procuring a software system) need to balance the costs and benefits of applying scarce resources to make software systems safe. That is, the level of safety afforded by a software system is a function of the level of resources expended to address controllable inputs and outputs to a software system; inputs and outputs from the environment can sometimes be anticipated but not necessarily controlled.

There are a plethora of conditions that can inject risk into software system artifacts. Software system artifacts are produced as a result of enacting a sofiware process model. This is also true for hardware, firmware, and "skinware" (i.c., human factors). The risk threshold triggered as a result of the occurrence of risk conditions is a moving target. Some enterprises elect to place their risk maıagement on others by paying insurance premiums. The federal government, per MIL-STD-882C, places the results of risk into four categories: (1) negligible, (2) marginal, (3) critical, and (4) catastrophic. Every program is unique; therefore, private industry and the government determine what is an acceptable risk level on a case-by-case basis.

When a condition or combination of conditions occurs that pushes a system (or component of a system) past the risk threshold, mishaps can occur. Performance of a system can be degraded while not crossing the risk threshold. Risks-which can lead to losses-can be classified into three elements. These include

- Deficient Task Preparedness: A worker not properly trained to perform the assigned job, project not thoroughly planned or funded, no manuals, etc. For instance, using a $\mathrm{C}$ programmer with no Ada experience or training to development Ada code with stringent schedule constraints.

- Unregulated Performance: Not complying with policies and procedures, not working with standards or lack of adequate standards, producing poor quality products, etc. For example, taking a software patch and installing it into an operational system without adequately testing the patch, or writing software code before adequately completing requirements definition.

- Environmental Conditions: There are a number of environmental conditions that may impact a software engineer's ability to do his job. For instance, improper lighting, screen glare, insufficient computer hardware or memory, the wrong software development tools for the job, lack of security, etc.

These three elements provide a basis for characterizing sound engineering principles and practices. To be effectively implemented they must be tailored to address specific program requirements. For example, some of the problems associated with deficient task preparedness, unregulated performance, and environmental conditions during software system development will differ for as the result of enacting software process models based upon rapid prototyping versus MIL-STD-2167A [6] software life-cycle models. The risks associated with these three elements, either individually or in combination, may surpass the risk threshold and therefore lead to errors introduced into the software process. Errors can occur during any of the system life-cycle phases. Moreover, latent errors could potentially lead to a system failure and potential loss after deployment as shown in Figure 2.

Deficient task preparedness, unregulated performance, and environmental conditions appear as clouds floating over the Spiral Model. They are intentionally represented this way to highlight volatility of the scope 


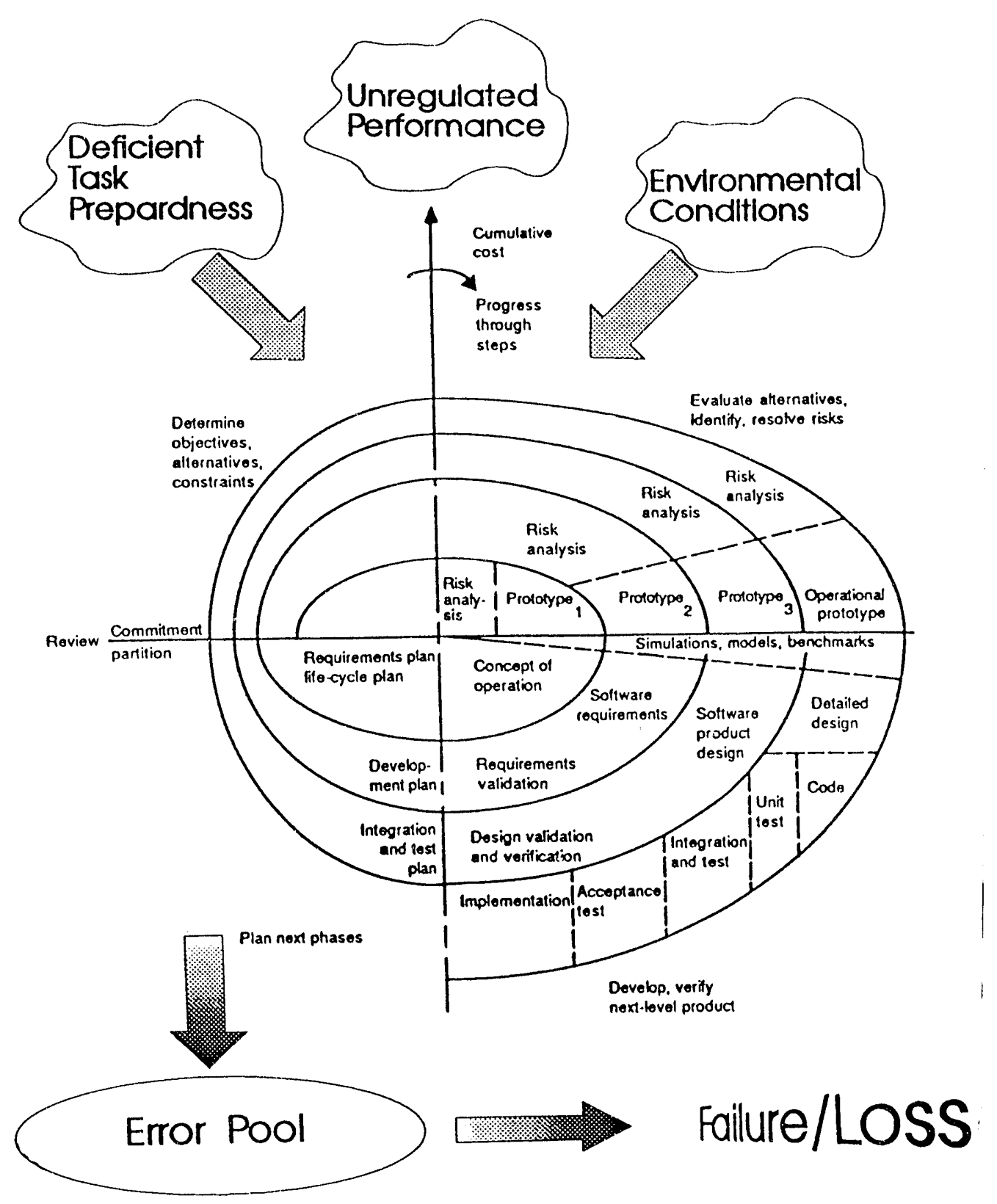

Figure 2. Risk-Based Software Safety Model

and weight that they will bear on the software development effort. These clouds permeate the spiral model, from initial risk analysis to implementation. As the software progresses through the iterative stages, inevitably software errors will propagate. The number and the potential criticality of the errors bears a direct relation to the efforts of the project manager and development tcam-in terms of understanding and managing deficient task preparedness, unreguluted performance, and environmental conditions.
During enactment of a spiral model, potential risks are identified and addressed. However, some risks will not be readily visible unless additional resources are expended. The value and utility of expending additional resources will vary between system users and developers. For example, due to budget constraints or market pressure, an enterprise might be willing to release a software product with known "non-critical" software errors in order to introduce the product into the market before its competitors or to rely on customers (i.c., users of the sof- 
tware-controlled system) to "debug" the product. However, when conditions arise or influence the system, thes latent errors, by themselves or in concert with other system influences, may cause a mishap-and ultimately a loss.

An example of an Unregulated Performance item is program testing and verification. The return on investment from performing these activities can be difficult to quantify. For example, “. . . quantification of reliability in the presence of design faults has been found to be infeasible whether applied to hardware or software (standard or fault tolerant)" [5]. Given that there are limited resources to test and verify software systems, it will be incumbent on management to allocate sufficient resources to ensure safety. As the complexity of systems increases, so should the budget to match the accepted level of risk.

Control of risk can be applied at any time during the development phase, or post-implementation. Operator error is often cited for failures which occur after a system is fielded. In contrast, system failures attributable to software errors can often be traced back to specification and other high-level software system artifacts, or to modifications to a software system made during the postdeployment phase of the software system life-cycle.

The following examples provide a hasis for understanding the necessity for the Risk-Based Software Safety Model for assessing causes and effects contributing to accidents, as well as performing risk-based costbenefit analysis.

\subsection{Case 1. Public Telephone System}

DSC Communications of Plano, Texas, a manufacturer of telephone call-routing computers modified four lines of computer code for a module that is part of the public telephone system. The installed software patch resulted in a series of network failures that disrupted local telephone service for 10 million telephone customers in the United States [1]. The software error-induced failure is a dramatic example of the consequences resulting from scemingly isolated software glitches buried amid millions of lines of computer code. It also demonstrates that software should be considered in a systems context. While installing the software patch, DSC failed to install algorithms needed by the telephone system to tolerate routine malfunctions.

DSC managers and engineers failed to adequately test the patch-they admitted that they had not put the software upgrade through a customary 13-week test because the change entailed only a few lines of new code. As a result of the system failure, the Chesapeake \& Potomac Telephone Co, (C\&P) offered refunds to customers who used operators to place local calls during the outage. The C\&P rate for operator-assisted local calls is $\$ 1.55$. Given that 6.3 million telephone lines were af- fected and assuming one-forth of C\&P customers required oyerator assistance, a tangible to - of $\$ 2.4 \%$ million could have been realized by the telephone company. These costs do not reflect the losses experienced by corporate customers. For example, an inoperable telephone system disrupts businesses which rely on the system as their primary link to their suppliers and customers, such as the financial and airline industry. Some safety-critical system, such as air traffic control (ATC) systems, depend heavily on the public telephone system. Thus, a telephone system outage has the potential to contribute to failures in other critical systems. Costbenefit analyses based on a combination of technical and social factors can provide enterprises like DSC with information from which to make decisions about their software processes in relation to the risks associated with their actions.

\subsection{Case 2 Therac-25 System}

The Therac-25, a medical electron accelerator developed by Atomic Energy of Canada Limited (AECL), is recognized to have caused a number of deaths and serious injuries between June 1985 and January 1987. The device is used to destroy tumors whiles causing minimal damage to surrounding healthy tissue. Apparently, there were a number of latent software errors embedded in the software controlling the emanation of radiation. This, combined with a lack of electromechanical interlocks, for monitoring safe, or acceptable levels of radiation, led to the mishaps. The software for the Therac-25 was adapted from Therac- 6 software. The software engineers also reused software routines from the Therac-20. Leveson and Tumer [10] state

The software error is just a nuisance on the Therac-20 because this machine has independent hardware protective circuits for monitoring the electron beam scanning. The protective circuits do not allow the beam to turn on so there is no danger of radiation exposure to a patient. While the Therac- 20 relies on mechanical interlocks for monitoring the machine, the Therac- 25 relies largely on software.

Some of the user actions and software errors contributing to mishaps include the following: use of editing keys to cursor up, backspace, and carriage return; data entry routines that allowed the code to proceed to activate the device while there was a "failure of the software interlock; cryptic malfunction messages, which were occasionally misinterpreted by the operator; and errors in the software sctup table.

From their efforts to reconstruct the software process used by the AECL engineers to develop the soft- 
ware controlling the Therac-25, Leveson and Turner note ilat neithor AECI, nor AECL'S customers ars willing in freely exchange information about the software process or failures, thus contributing to the void of information available on software-related catastrophic mishaps.

In terms of the Risk-based Software Safety Model, it is difficult to improve the software process without this type of information; that is, there is little information on the mishaps to provide fecdback to other software process activities. In particular, feedback protocols-such as the one proposed by Sherif for software safety analysis [16] are not useless unless there is software process information on system failures is accessible.

For this example, one could categorize the system failures into the categories of deficient task preparedness, unregulated performance and environmental conditions. The following highlight some of the problems with the Therac-25:

Deficient Task Preparedness

- Questionable training and certification of lead software developer

- Software failures were not considered during hazard analysis

- Failed to follow recommended software modifications

Unregulated Performance

- No System Safety Program Plan

- Inadequate software development standards, policies and procedures

- Poor operating procedures

- Lack of documentation on software specification and test plans

Environmental Conditions

- No hardware safety interlocks or backups

- Data entry speed contributed to error

- Contusing and non-specific crror codes

- Poor screen refresh

In addition, social issues need to be considered in the decision making process. For example, what is the value and utility associated with providing higher levels of assurance for medical equipment such as the Therac25? How do we quantify the ill-will of the public toward AECL and the medical profession as the result of an accident due to a system mishap? Note that in this last question we did not refer to a software failure because software safety is only meaningful in a system context (i.e., in relation to hardware and human factors).

It is impossible from what we know of the telephone system and Therac-25 mishaps to determine whether decision makers at either DSC or AECL might have modified the software processes they followed had they systematically considered risk factors. In the case of
DSC, contravening the existing software process testing activ: $y$ restilled in a $k$... for both DSC, telephon companies, and customers of the telephone companies. In the case of AECL, it is not known whether a formal plan was in place to manage software safety-related activities.

\section{CONCLUSIONS}

History shows us that greater emphasis must be placed on task preparedness, regulating performance, and environmental conditions. Efficacy losses, which usually go undocumented, comprise the most significant losses that the business and industry experience. The blinders must be removed to view the greater picture in terms of real and potential losses.

The Risk-Based Software Safety Model provides a basis for performing risk cost-benefit analysis of software safety-related activities in a system context. The model is intended to assist its users in obtaining a greater awareness of risk associated with application of software engineering principles and practices for a particular context, and managing real and potential risks of software systems while balancing the expected costs with the expected benefits of making a software-controlled system safe.

The model can be used post-mishap to quantify hazards and concomitant costs; the case studies illustrate the need for post-mishap analysis. The model can be used to quantify -risk where possible during the system life cycle and to plan in conjunction with cost-benefit analysis activities for eliminating the mitigating risks.

We are currently working on an example that demonstrates the use of the Risk-based Software Safety Model in conjunction with Bochm's Spiral Model.

\section{REFERENCES}

[1] E. L. Andrews, "Computer Maker Says Tiny Software Flaw Caused Phone Disruption," New York Times, 10 July 1991.

[2] F. Bird and R. Loftus, LO\$\$ Control Management. Loganville, Ga.: Institute Press, 1976.

[3] B.W. Boehm, "A Spiral Model of Software Development and Enhancement," Computer 21, 5 (1988), pp. 61-72.

[4] J. Boweil and V. Stavridou, Safety-Critical Systems, Formal Methods and Standards. Tech. Rep. PRGTR-5-92, Oxford Univ. Computing Lab., Oxford, England, 1992.

[5] R.W. Butler and G.B. Finclli, "The Infeasibility of Experimental Quantification of Life-Critical Software Reliability," Proc. Sixth Annual Conf. on Com- 
puter Assurance. Los Alamitos, Calif.: IEEE Computer Soc. Press, 1>91, pp. i57-162.

[6] Department of Defense. Defense System Software Development. U.S. MIL-STD-2167A, 1985.

[7] Department of Defense. System Safety Program Requirements. Draft U.S. MIL-STD-882C, 1991.

[8] H.W. Heinrich and D. Petersen, Industrial Accident Prevention. New York: McGraw-Hill, 1980.

[9] M.I. Kellner, "Softw'are Process Modeling Support for Management Planning and Control." Proc. First Int. Conf. on the Sofiware Process. Los Alamitos, Calif.: IEEE Computer Soc. Press, 1991, pp. 8-28.

[10] N.G. Leveson and C.S. Turner, An Investigation of the Therac-25 Accidents. Tech. Rep. CS-92-108, Univ. of California, Irvine, Calif., Nov. 1992.

[11] N.G. Leveson, "Software Safety in Embedded Computer Systems," Commun. ACM 34, 2 (1991), pp. 3446.

[12] N.G. Leveson, "Software Safety: Why, What, and How," ACM Comput. Surv. 18, 2 (1986), pp. 125163.

[13]C.E. Marcum, Modern Safety Management Practice. Morgantown, W.Va.: Worldwide Safety Institute, 1978.

[14] J.B. Michacl and S.C. Fortier, "Understanding and Managing Software Safety Assessment Activities," Proc. IASTED Int. Conf. on Reliability, Quality Control and Risk Assessment. Anaheim, Calif.: IASTED-ACTA Press, 1992, pp. 28-31.

[15] D.L. Parnas, A.J. van Schouwen, and S.P. Kwan, "Evaluation of Safety-Critical Software," Commun. ACM 33,6 (1990), pp. 636-651.

[16] Y.S. Sherif, "Software Safety Analysis-The Characteristics of Efficient Technical Walkthroughs," Microelectronics and Reliability 32, 3 (1992), pp. 407-414.

\section{ACKNOWLEDGMENTS}

We thank the reviewers for their helpful comments. This work was not funded through Argonne National Laboratory.

\section{DISCLAIMER}

This report was prepared as an account of work sponsored by an agency of the United States Government. Neither the United States Government nor any agency thereof, nor any of their employees, makes any warranty, express or implied, or assumes any legal liability or responsibility for the accuracy, completeness, or usefulness of any information, apparatus, product, or process disclosed, or represents that its use would not infringe privately owned rights. Reference herein to any specific commercial product, process, or service by trade narne, trademark, manufacturer, or otherwise does not necessarily constitute or imply its endorsement, recommendation, or favoring by the United States Government or any agency thereof. The views and opinions of authors expressed herein do not necessarily state or reflect those of the United States Government or any agency thereof. 

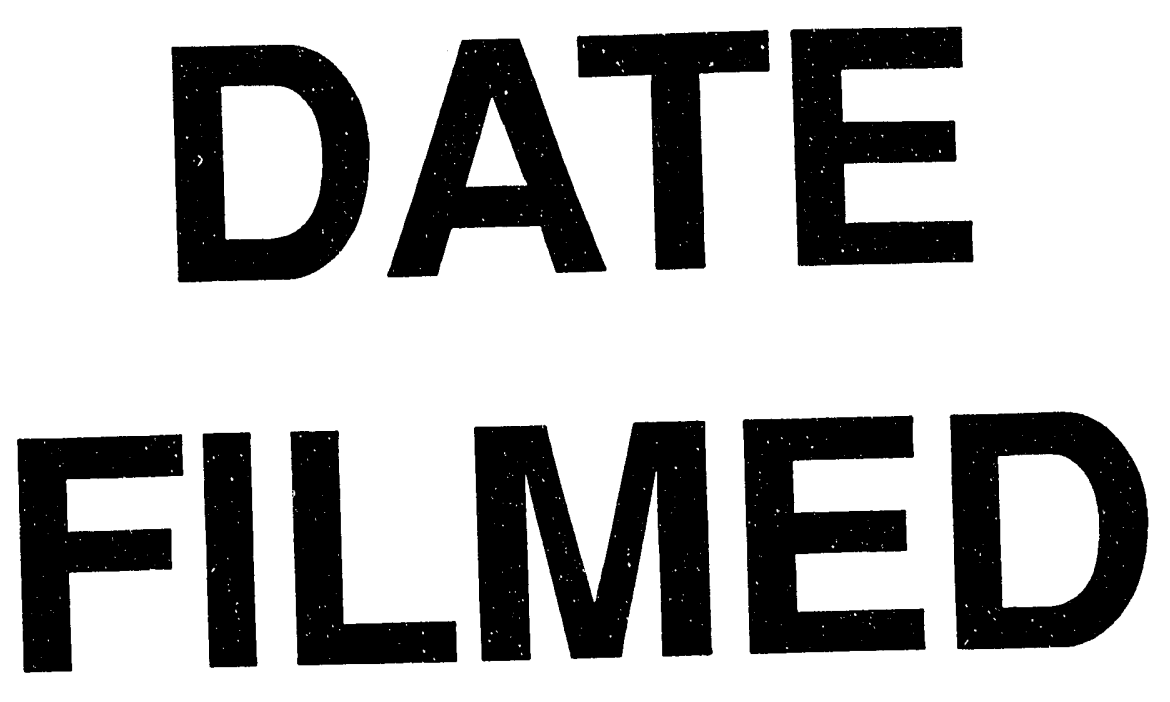

$8 / 4 / 93$
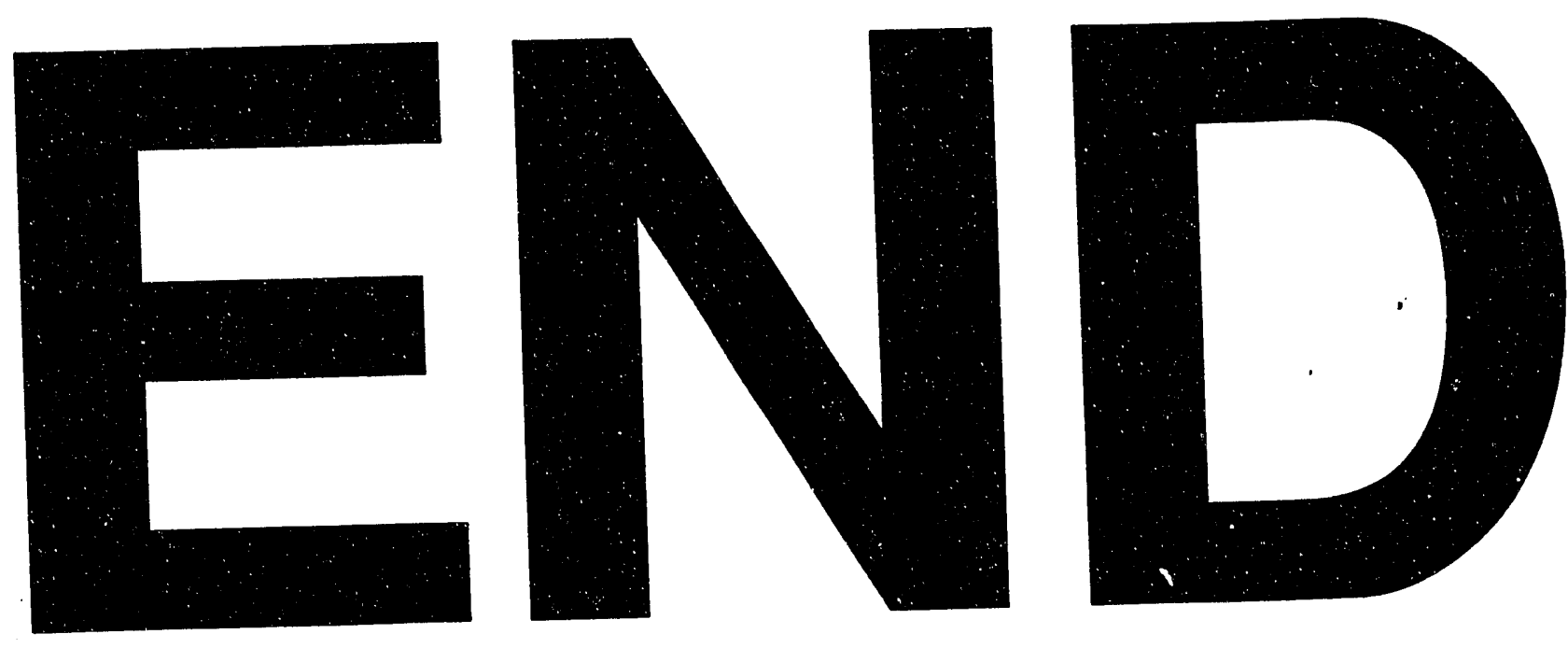
